\title{
Malignant Pleural Mesothelioma presenting with Cardiac Tamponade- A Rare Case report and Review of the literature
}

\author{
Apoorva Jayaranagaiah ${ }^{1}$, Pramod Theetha Kariyanna ${ }^{2}$, Naga Koteshwari Sucharitra Chidella ${ }^{3}$, Navneet Singh ${ }^{4}$, Jason Green ${ }^{4}$, Moro O. Salifu \\ and Samy I McFarlane ${ }^{4 *}$ \\ ${ }^{1}$ Department of Internal Medicine, Wake Forest University- Baptist Health, Winston-Salem, North Carolina, USA \\ ${ }^{2}$ Division of Cardiovascular Disease, Department of Internal Medicine, State University of New York, Downstate Medical Center, Brooklyn, New York, USA \\ ${ }^{3}$ Division of Hematology and Oncology, Department of Internal Medicine, University of Texas Southwestern Medical Center, Dallas, Texas, USA \\ ${ }^{4}$ Department of Internal Medicine, State University of New York, Downstate Medical Center, Brooklyn, New York, USA
}

\begin{abstract}
Mesothelioma is a rare tumor of the pleura, peritoneum, pericardium or tunica vaginalis. About 2,500 cases are diagnosed annually in the United States. Mesothelioma often presents with pleuritic chest pain and dyspnea related to local invasion; distal metastasis and lymphadenopathy at the time of diagnosis is rare. Pericardial involvement in mesothelioma is related to direct invasion of the tumor. We here present a 71 year-old-male who presented with pleuritic chest pain and dyspnea, noted to have diffuse ST-segment elevation in EKG and cardiac tamponade physiology on 2D echocardiogram in who imaging subsequently revealed left upper lung mesothelioma. A pericardial window was created following which tamponade resolved. The pericardial biopsy did not show any mesothelioma cells or fibrous plaques. Computer tomography revealed regional lymphadenopathy in the chest. Disrupted cardiac lymphatic flow due to tumor mesothelioma induced lymphadenopathy is likely cause of the cardiac tamponade in this patient. This is the second ever reported case of pleural mesothelioma without a direct pericardial invasion that presented with cardiac tamponade.
\end{abstract}

\section{Introduction}

Mesothelioma is a rare malignant neoplasm of mesothelial cells that may arise in the pleura, peritoneum, pericardium or tunica vaginalis. Pleural mesothelioma usually presents with chest pain and/or dyspnea, however it rarely presents with cardiac tamponade. Lymphadenopathy at the time of mesothelioma diagnosis is also rare.

Cardiac or pericardial involvement in pleural mesothelioma is usually due to direct invasion by the tumor. We here present a case of pleural mesothelioma located in the left upper lung that presented with cardiac tamponade. Associated mediastinal lymphadenopathy was noted in computed tomography.

Pericardial lymphatic drain pericardial fluid to mediastinal lymph nodes. Mediastinal lymphadenopathy likely from pleural mesothelioma metastasis disrupted the pericardial fluid drainage, thus resulting in pericardial fluid accumulation and cardiac tamponade.

\section{Case Presentation}

A 71 year-old-male with past medical history of hypertension, hyperlipidemia, diabetes, chronic obstructive pulmonary disease and marijuana abuse presented with intermittent retrosternal pleuritic chest pain for two weeks, sharp in nature, 7/10 in intensity, non-radiating, and aggravated by sitting up from a lying position, deep breathing, and exertion. The patient reported intermittent nonproductive cough, fatigue, decreased appetite and a 10-pound weight loss in the past eight months. Chest radiography and physical exam findings were all noted as normal one year prior to presentation. He had a 40 pack year's history of smoking; he quit 25 years ago.
On examination, he was afebrile, pulse rate 88 beats per minute, blood pressure of $133 / 70 \mathrm{mmHg}$, with an oxygen saturation of $98 \%$ on room air. An electrocardiogram revealed diffuse ST-segment elevation. A chest radiograph revealed cardiomegaly, congestion, and a pleural-based opacity in the left upper lung field. Transthoracic echocardiography showed a left ventricular ejection fraction of $30 \%$, grade 1 diastolic dysfunction, inferior vena cava dilation with blunting of respirophasic changes (less than 50\% variation), and a large circumferential pericardial effusion with "swinging" of the heart, suggestive of cardiac tamponade physiology. Laboratory investigations revealed a hemoglobin of $9.3 \mathrm{~g} / \mathrm{dL}$, glycosylated hemoglobin at $9.4 \mathrm{~g} \%$, troponin I obtained 8 hours apart were in normal range $(0.014 \mathrm{ng} / \mathrm{mL}$ and $0.024 \mathrm{ng} / \mathrm{mL}$ ). Computed tomography of the chest with contrast revealed a $4.5 \mathrm{~cm}$ left upper lobe mass, left hilar and mediastinal lymphadenopathy, and a large pericardial effusion. A pericardial window was placed and $750 \mathrm{ml}$ of serosanguinous pericardial fluid was drained. Pericardial fluid cytology was negative for malignant cells and bacteria. Elevated lactate dehydrogenase (7157 units per liter) and glucose level (266 milligrams per deciliter), reactive mesothelial cells and numerous white blood cells were noted. A computed

${ }^{\star}$ Correspondence to: Samy I McFarlane, MD, MPH, MBA, FACP, Distinguished Teaching Professor and Associate Dean, Residency Program Director, Department of Internal Medicine, State University of New York-Downstate Medical Center, 450 Clarkson Avenue, Box 50, Brooklyn, New York, 11203, Tel: 718-270-3711; Fax: 718-270-6358; E-mail: Samy.mcfarlane@downstate.edu

Received: May 15, 2018; Accepted: May 25, 2018; Published: May 30, 2018 
tomography-guided biopsy of the left lung mass was performed; hematoxylin and eosin stains showed poorly differentiated malignant neoplasm. Immunohistochemical analysis revealed malignant pleural mesothelioma. The pericardial biopsy did not show any mesothelioma cells or fibrous plaques. The patient has been lost to follow-up since the diagnosis.

\section{Discussion}

Malignant mesothelioma is a rare malignancy that arises from the mesothelial lining of pleura, peritoneum and less commonly pericardium and tunica vaginalis [1]. In 1960, Wangner et al. established the association between asbestos exposure and malignant pleural mesothelioma [2]. Though the use of asbestos has been widely abandoned since 1980's, the mortality rate of mesothelioma is still on rising due to the long latency (14- 72 years) between exposure and development of mesothelioma [3]. Mesothelioma is usually diagnosed in the fifth decade of life; the disease has a strong male predominance when asbestos exposure is involved.

Approximately 2,500 cases of mesothelioma are diagnosed annually in the United States, of which 2000 cases are in men and 500 are in women. Since 1983, the incidence of the disease has been stable in women and men $<75$ years of age. However, the incidence is rising in men $>75$ years of age; the maximum at risk are the birth cohort of men born between 1925 to 1929 [4]. 80\% of patients with malignant pleural mesothelioma have asbestos exposure; only $10 \%$ of those exposed to asbestos developed malignant pleural mesothelioma $[5,6]$. Another suggested association with malignant mesothelioma is simian virus 40 (SV-40) [7]; however recent studies have questioned this association [8-10]. Idiopathic or spontaneous mesothelioma has also been described [11]. Chromosomal abnormalities commonly associated with mesothelioma are the deletion of chromosomal regions 1 p, 3p, 9p, 6q and deletion of chromosome 22 [12].

Malignant pleural mesothelioma often presents with chest pain, dyspnea or both $[13,14]$. Chest pain is characteristically dull or boring. Pleuritic chest pain and dyspnea, the common initial symptoms can become progressively worse with the progression of the disease and patients may subsequently develop weight loss, anorexia and night sweats. Local invasion of the mediastinum may lead to diaphragmatic paralysis, Horner's syndrome, superior vena cava syndrome, and vocal cord paralysis. Malignant pleural mesothelioma can be asymptomatic and diagnosed as an incidental mass on radiography [15]. Regional lymphadenopathy and metastases are rarely present at diagnosis [16]. Pericardial involvement is also rare, however cases of pleural mesothelioma presenting with cardiac tamponade and benign effusiveconstrictive pericarditis have been reported [17]. Concomitant benign effusive-constrictive pericarditis in patients with pleural mesothelioma has been previously reported $[18,19]$. Table 1 summarizes pericardial involvement in various case series of pleural mesothelioma.
The case we present here is that of a malignant pleural mesothelioma that presented with cardiac tamponade. In our patient, malignant pleural mesothelioma was noted in left upper lobe with no direct pericardial involvement as evidenced by imaging or pericardial biopsy. However, the patient had mediastinal lymphadenopathy which possibly led to the development of cardiac tamponade. Boulanger et al. clearly established the vital role of pericardial lymphatics in the drainage of pericardial fluid [25]. Pericardial lymphatic drainage can increase up to four times with an increase in pericardial fluid volume or pressure. Hence, any obstruction to pericardial lymphatic drainage can result in pericardial effusion or cardiac tamponade [26]. Pericardial lymphatics from the ventral surface of the heart accompany phrenic nerves cranially and terminate in anterior right, left, and transverse mediastinal lymph nodes; they caudally drain into diaphragmatic or pre-pericardial lymph nodes. Lymphatics from the lateral pericardium drain into anterior mediastinal, tracheobronchial, lateropericardial, prepericardial and posterior mediastinal (juxtaesophageal) lymph nodes [27]. Hence, in the above-presented case, it can be expected that mediastinal lymphadenopathy disrupted the pericardial fluid drainage via pericardial lymphatics progressively leading to the development of a pericardial effusion and subsequently cardiac tamponade (Figures 1-6).

\section{Conclusion}

Pleural mesothelioma is a rare malignant neoplasm that usually presents in men exposed to asbestos. Pericardial effusion or cardiac

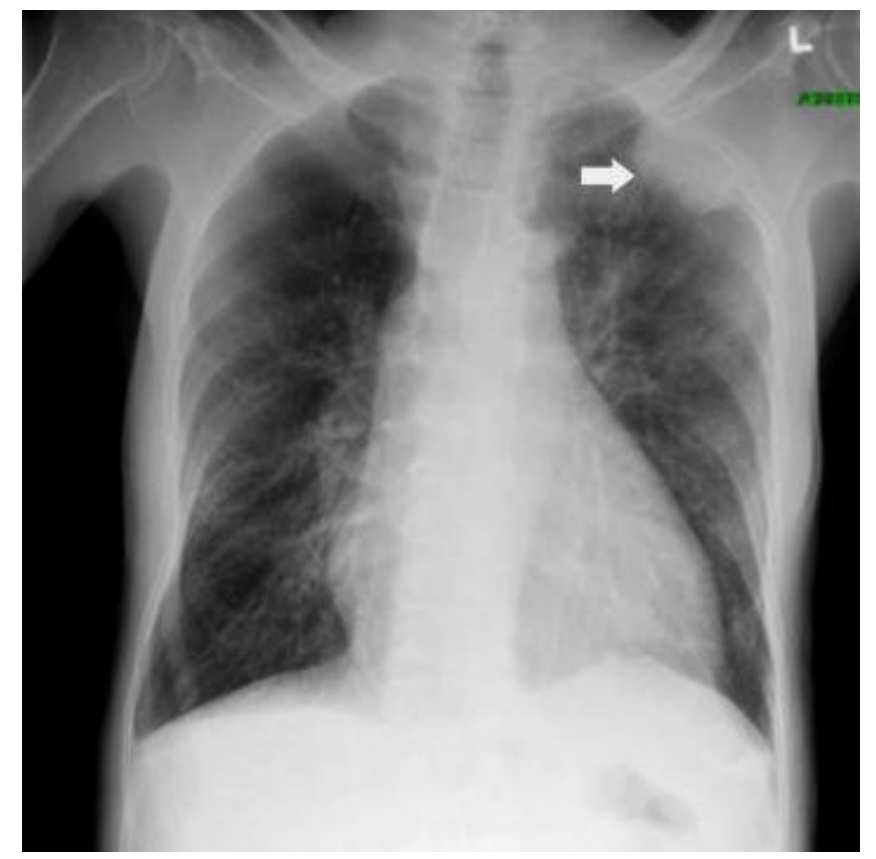

Figure 1. Radiography of the patient revealing pleural-based opacity left upper lung field. Also cardiomegaly and mild pulmonary congestion may be noted.

Table 1. Summary of pericardial involvement in various case series of pleural mesothelioma

\begin{tabular}{|c|c|c|c|}
\hline Case series by & $\begin{array}{c}\text { Number of cases reviewed in the } \\
\text { case series }\end{array}$ & $\begin{array}{c}\text { \% of cases with cardiac/pericardial } \\
\text { involvement }\end{array}$ & Observation \\
\hline Roberts et al. $[20]$ & 32 & $19 \%$ & Pericardial and epicardial involvement of tumor without benign fibrosis \\
\hline Chahinian et al. $[21]$ & 69 & $16 \%$ & $\begin{array}{c}12 \% \text { had pericardium replaced by mesothelioma } \\
4 \% \text { had myocardial invasion }\end{array}$ \\
\hline Ruffie et al. $[22]$ & 332 & $49 \%$ & $\begin{array}{c}49 \% \text { had pericardial involvement } \\
5 \% \text { died of pericardial constriction or tamponade }\end{array}$ \\
\hline Law et al. $[23]$ & 140 & $0 \%$ & - \\
\hline Antman et al. $[24]$ & 180 & $0 \%$ & - \\
\hline
\end{tabular}




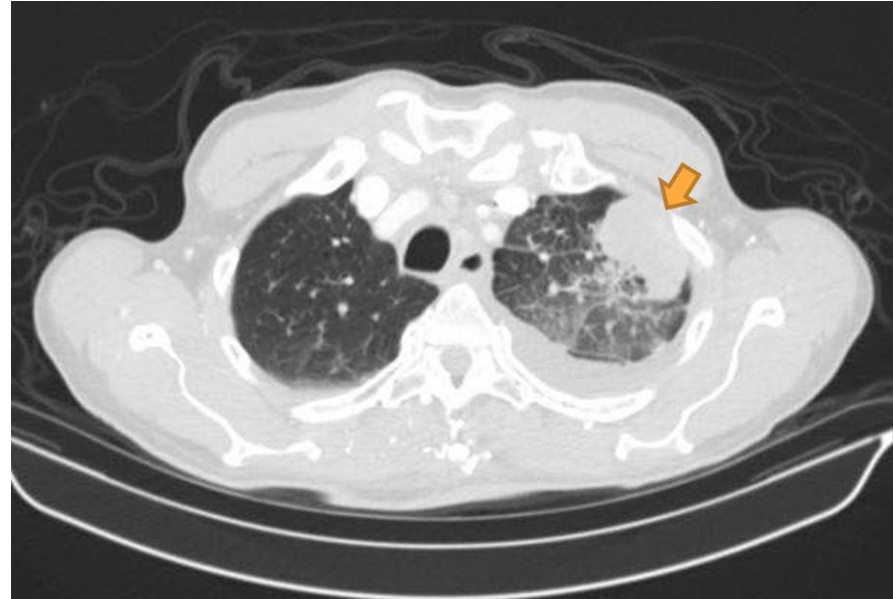

Figure 2. Computed tomography (axial view) of the patient showing pleural based mass (indicated by brown arrow) later found to be pleural mesothelioma on immuno-histological examination of the biopsy.



Figure 3. Computed tomography (coronal view) of the patient showing pleural based mass (indicated by brown arrow) later found to be pleural mesothelioma on immuno-histological examination of the biopsy. Mediastinal lymphadenopathy is also noted (indicated by yellow arrow), also huge pericardial effusion may be noted.

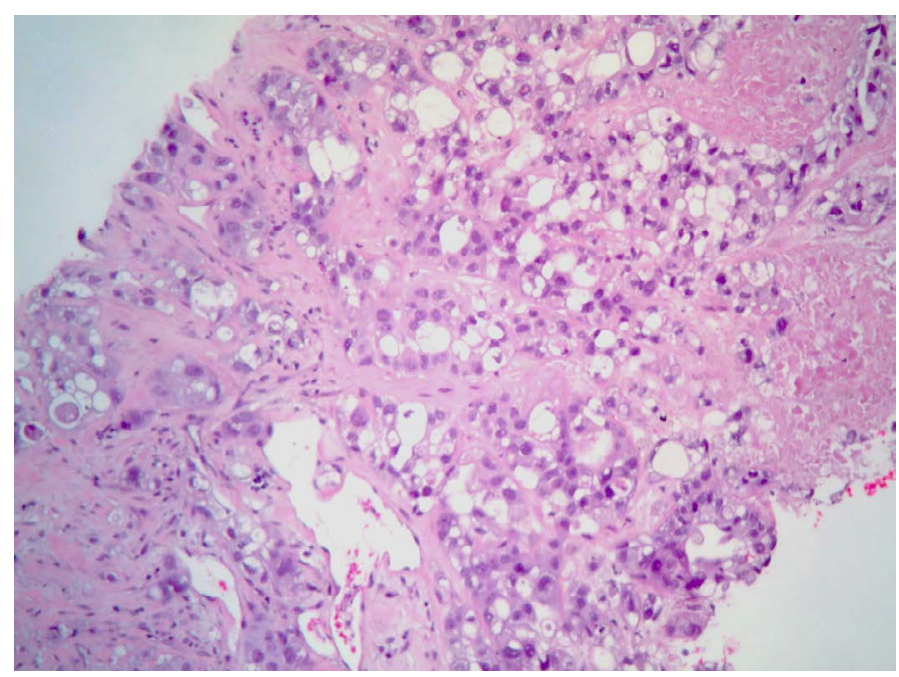

Figure 4. Hematoxylin and eosin staining of the pleural based mass revealing epithelioid mesothelioma (glandulo-tubular pattern).

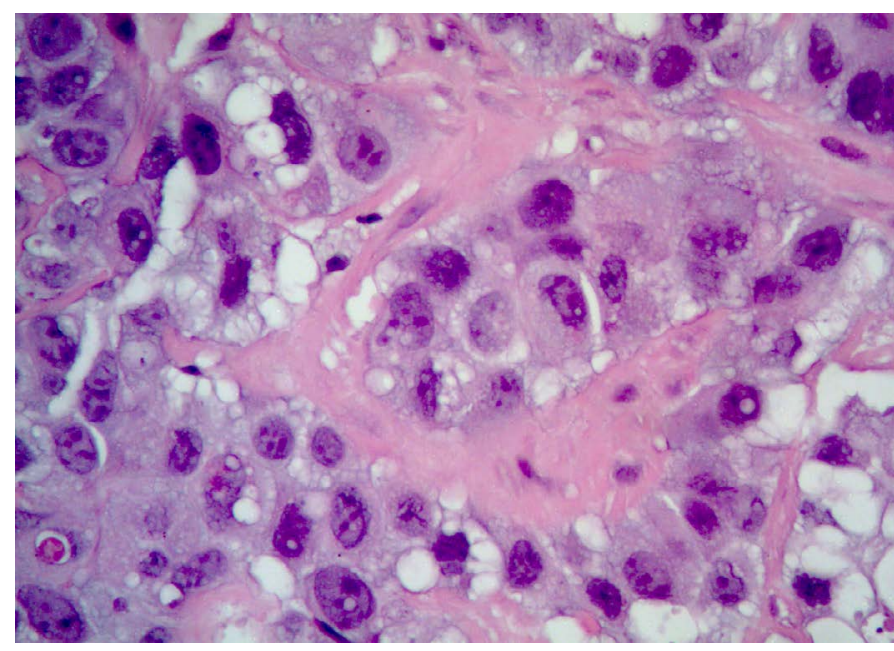

Figure 5. Hematoxylin and eosin staining of epithelioid mesothelioma. Plasmacytoid appearance with abundant cytoplasm and nuclear atypia may be noted.

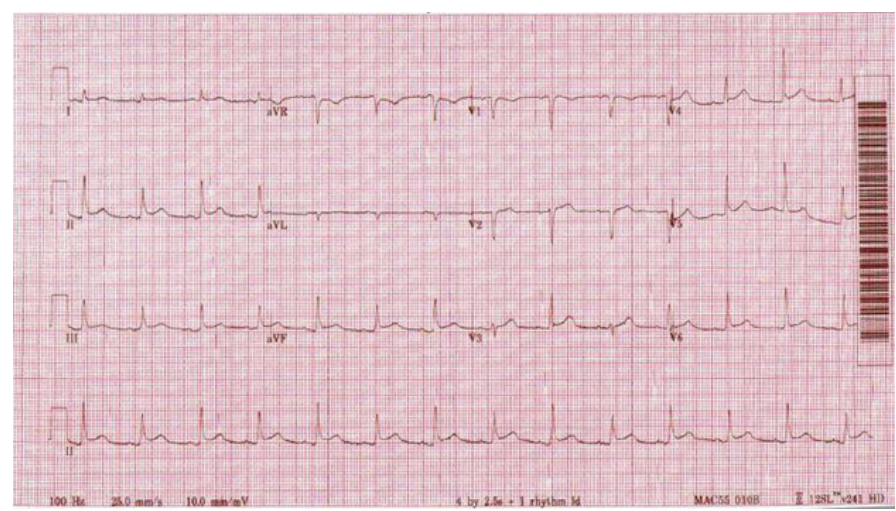

Figure 6. Diffuse ST-segment elevation, consistent with acute pericarditis.

tamponade in pleural mesothelioma often happens as a result of pericardial lymphatic obstruction. Disruption of the pericardial lymphatic flow from mediastinal lymphadenopathy led to the development of cardiac tamponade. To the best of our knowledge, this is the second ever reported case of pleural mesothelioma without a direct pericardial invasion that presented with cardiac tamponade.

\section{Acknowledgement}

We are grateful to Dong.S.Kim, M.D. and Cheng Cheng Huang, M.D., Department of Pathology, Brookdale University Hospital and Medical Center to provide the immuno-histological diagnosis and images.

\section{Funding}

This work is sponsored in part by the Brooklyn Health Disparities Center NIH grant \#P20 MD006875.

\section{References}

1. Jett J, Aubry M (2004) Clinical Respiratory Medicine. Edited by Albert, Spiro, Jett (2ndedn), Philadelphia, Mosby, 735-741.

2. Wagner JC, Sleggs CA, Marchand P (1960) Diffuse pleural mesothelioma and asbestos in the North Western Cape Province. Br J Ind Med 17: 260-271. [Crossref]

3. Bianchi C, Giarelli L, Grandi G, Brollo A, Ramani L, et al. (1997) Latency periods in asbestos-related mesothelioma of the pleura. Eur J Cancer Prev 6: 162-166. [Crossref] 
4. Peto J, Decarli A, La Vecchia C, Levi F, Negri E (1999) The European mesothelioma epidemic. Br J Cancer 79: 666-672. [Crossref]

5. Chahinian AP, Pajak TF, Holland JF, Norton L, Ambinder RM, et al. (1982) Diffuse malignant mesothelioma: prospective evaluation of 69 patients. Ann Intern Med 96: 746-755. [Crossref]

6. Selikoff IJ, Hammond EC, Seidman H (1980) Latency of asbestos disease among insulation workers in the United States and Canada. Cancer 46: 2736-2740. [Crossref]

7. Stenton SC (1997) Asbestos, Simian virus 40 and malignant mesothelioma. Thorax 52: 52-57. [Crossref]

8. Lopez-Rios F, Illei PB, Rusch V, Ladanyi M (2004) Evidence against a role for SV40 infection in human mesotheliomas and high risk of false-positive PCR results owing to presence of SV40 sequences in common laboratory plasmids. Lancet 364: 1157-1166. [Crossref]

9. Manfredi JJ, Dong J, Liu WJ, Resnick-Silverman L, Qiao R, et al. (2005) Evidence against a role for SV40 in human mesothelioma. Cancer Res 65: 2602-2609. [Crossref]

10. Leithner K, Leithner A, Clar H, Weinhaeusel A, Radl R, et al. (2006) Mesothelioma mortality in Europe: impact of asbestos consumption and simian virus 40. Orphanet $J$ Rare Dis 1: 44. [Crossref]

11. Marchevsky AM, Wick MR (2003) Current controversies regarding the role of asbestos exposure in the causation of malignant mesothelioma: the need for an evidence-based approach to develop medicolegal guidelines. Ann Diagn Pathol 7: 321-332. [Crossref]

12. Papp T, Schipper H, Pemsel H, Bastrop R, Muller KM, et al. (2001) Mutational analysis of N-ras, p53, p16INK4a, p14ARF and CDK4 genes in primary human malignant mesotheliomas. Int J Oncol 18: 425-433. [Crossref]

13. British Thoracic Society Standards of Care Committee (2007) BTS statement on malignant mesothelioma in the UK, 2007. Thorax 62: ii1-ii19. [Crossref]

14. Stewart DJ, Edwards JG, Smythe WR, Waller DA, O’Byrne KJ (2004) Malignant pleural mesothelioma-an update. Int J Occup Environ Health 10: 26-39.

15. Yates DH, Corrin B, Stidolph PN, Browne K (1997) Malignant mesothelioma in south east England: clinicopathological experience of 272 cases. Thorax 52: 507-512. [Crossref]
16. Elmes PC, Simpson JC (1976) The clinical aspects of mesothelioma. Q J Med 45: 427-449. [Crossref]

17. Meysman M, Noppen M, Demeyer G, Vincken W (1993) Malignant epithelia mesothelioma presenting as cardiac tamponade. Eur Heart J 14: 1576-1577. [Crossref]

18. Weir NA, Gerstenhaber B (2001) A Case of Pleural Mesothelioma with EffusiveConstrictive Pericarditis. Yale J Biol Med 74: 159-163. [Crossref]

19. Yilling FP, Schlant RC, Hertzler GL, Krzyaniak R (1982) Pericardial mesothelioma Chest 81: 520-523.

20. Roberts GH (1976) Distant visceral metastases in pleural mesothelioma. Br J Dis Chest 70: 246-250. [Crossref]

21. Chahinian AP, Pajak TF, Holland JF, Norton L, Ambinder RM, et al. (1982) Diffuse malignant mesothelioma. Prospective evaluation of 69 patients. Ann Int Med 96: 746755. [Crossref]

22. Ruffle P, Feld R, Minkin S, Cormier Y, Boutan-Laroze A, et al. (1989) Diffuse malignant mesothelioma of the pleura in Ontario and Quebec: a retrospective study of 332 patients. J Clin Oncol 7: 1157-1168. [Crossref]

23. Law MR, Hodson ME, Turner-Warwick M (1984) Malignant mesothelioma of the pleura: clinical aspects and symptomatic treatment. Eur J Respir Dis 65: 162-168. [Crossref]

24. Antman K, Shemin R, Ryan L, Klegar K, Osteen R, et al. (1988) Malignan mesothelioma: prognostic variables in a registry of 180 patients, the Dana-Farber Cancer Institute and the Brigham and Women's Hospital experience over two decades, 1965-1985. J Clin Oncol 6: 147-153. [Crossref]

25. Boulanger B, Yuan Z, Flessner M, Hay J, Johnston M (1999) Pericardial fluid absorption into lymphatic vessels in sheep. Microvasc Res 57: 174-86. [Crossref]

26. Vogiatzidis K, Zarogiannis SG, Aidonidis I, Solenov EI, Molyvdas PA, et al. (2015) Physiology of pericardial fluid production and drainage. Front Physiol 6: 62. [Crossref]

27. Eliskova M, Eliska O, Miller AJ (1995) The lymphatic drainage of the parietal pericardium in man. Lymphology 28: 208-17. [Crossref]

Copyright: (C2018 Jayaranagaiah A. This is an open-access article distributed under the terms of the Creative Commons Attribution License, which permits unrestricted use, distribution, and reproduction in any medium, provided the original author and source are credited. 